\title{
Faith-based and Community Organizations: Essential Partners in Pandemic Influenza Preparedness
}

\author{
Scott Santibañez, MD, MPHTM \\ Commander, U.S. Public Health Service \\ Department of Health and Human Services \\ Centers for Disease Control and Prevention \\ Coordinating Center for Health Information and Service \\ National Center for Health Marketing \\ Division of Partnerships and Strategic Alliances \\ Atlanta, Georgia
}

\begin{abstract}
:
An influenza pandemic occurs when a new strain of influenza virus-one against which humans have little or no natural immunity-emerges with the ability to cause illness in humans and efficiently pass from person to person. A severe pandemic could change daily life by, for example, limiting travel and public gatherings, disrupting businesses, and requiring children to be dismissed from schools. Most significantly, such an event could cause increased sickness and death. Currently, there is no human influenza pandemic in the United States or overseas. However, it is not possible to know in advance how severe the next pandemic will be. If our country prepares now, we will be able to better withstand the impact of a pandemic and to help limit the spread of illness. Faithbased and community organizations (FBCOs) will be essential partners in protecting the public's health and safety when an influenza pandemic occurs. This article provides information for religious organizations including mosques, faith-based social service providers, social service agencies, and community organizations in preparing for and responding to an influenza pandemic.
\end{abstract}

Key words: Pandemic influenza, community-based organization, faith-based organization.

$\mathrm{W}$ hen asking about pandemic influenza one may hear from a variety of people ranging from those who do not believe it is a real problem, to those predicting doomsday scenarios, to those calling for careful preparedness planning. Faith-based and community-based organizations

Correspondence should be directed to

Scott Santibañez, MD, MPHTM

Commander, U.S. Public Health Service

Email: zqg5@cdc.gov
(FBCOs) are essential partners in helping people prepare for an influenza pandemic and in protecting the public's health and safety should an influenza pandemic occur. The purpose of this article is to help readers understand that the threat of pandemic influenza is real and to actively engage readers in preparing for a severe influenza pandemic.

What are the Different Types of Influenza?

There are three main categories of influenza: seasonal, avian, and pandemic. Each year in the United States, usually during the winter, seasonal influenza 
affects about $5-20 \%$ of the population. About 225,000 people are hospitalized, and approximately 36,000 people die from seasonal influenza each year. The best way to prevent seasonal influenza is to get a vaccine yearly.

Avian influenza is found mostly in birds. Infection of humans is very rare. However, avian influenza viruses sometimes develop the ability to more easily infect humans and spread readily from person to person. When this occurs, avian influenza viruses can cause influenza pandemics in humans.

\section{What is Pandemic Influenza?}

An influenza pandemic occurs when a new strain of influenza virus-one against which humans have little or no natural immunity-emerges with the ability to cause illness in humans and efficiently pass from person to person. Symptoms such as fever, cough, and muscle pain are similar to those seen with seasonal influenza, but, in a severe pandemic, $30 \%$ or more of the population would get sick, and more people would suffer from complications or die. A severe pandemic influenza virus would likely spread worldwide in a matter of months.

Influenza pandemics occurred three times in the past century and ranged considerably in severity. During the 20th century, for example:

- The 1918 influenza pandemic caused 20-50 million deaths worldwide,

- The 1957 influenza pandemic caused 1-2 million deaths, and

- The 1968 influenza pandemic caused 700,000-1 million deaths.

A severe pandemic could change daily life by, for example, limiting travel and public gatherings, disrupting businesses, and requiring children to be dismissed from schools. Most significantly, such an event could cause increased sickness and death. It is estimated that 90 million Americans could become ill, and nearly 2 million Americans could die in a severe pandemic. Even during a less severe pandemic, $30 \%$ or more of the population would get sick, and thousands of hospitalizations and deaths would occur.

Currently, there is no human influenza pandemic in the United States or overseas. However, leading public health experts at the Centers of Disease
Control and Prevention (CDC) and elsewhere agree that the threat of a pandemic is a question of "when" and "how severe" rather than "if" there will be another pandemic. Therefore, it is important to plan and prepare for a severe pandemic, just as Hurricane Katrina in 2005 demonstrated that communities need to plan and prepare for severe natural disasters. If the country prepares now, its citizens will be able to better withstand the impact of a pandemic and to help limit the spread of illness.

The United States is working with the World Health Organization (WHO) and other countries to strengthen detection and tracking of new influenza viruses. Scientists are closely watching the avian influenza A (H5N1) virus and other avian influenza viruses. The H5N1 virus has spread widely throughout bird populations across Asia, Africa, Europe, and the Middle East. It has infected long-range migratory birds and domesticated birds, including ducks and chickens. Accordingly, it is commonly referred to as an "avian" or "bird flu." Since 1997, this virus has affected more than 300 people worldwide, of which one half have died from the illness. Fortunately, so far, animal-to-human transmission has been inefficient, and human-to-human transmission extremely rare. Health officials are monitoring for mutations in H5N1 viruses that may increase their ability to spread easily among humans.

\section{Preventing the Spread of an Influenza Pandemic}

Once a pandemic begins, it is unlikely that its spread could be stopped. However, slowing the spread of a pandemic would provide more time to produce, distribute, and administer a vaccine and could prevent overwhelming the healthcare system. When an influenza pandemic starts, public health officials will determine its likely severity and recommend responsive actions at all levels of society, according to the Community Strategy for Pandemic Influenza Mitigation. ${ }^{1}$ Influenza viruses spread when infected people cough, sneeze, or talk, sending droplets and very small sprays into the air and into contact with other people. These viruses also spread when people touch contaminated objects and then touch their nose, mouth, or eyes. To prevent spreading influenza and respiratory infections in general, people should take actions such as covering their mouths and noses when coughing and sneezing and washing their hands frequently. During a severe 
influenza pandemic, large public gatherings may be canceled, and work schedules may be changed to decrease the spread of disease. Community-level mitigation actions could include the following recommendations:

- Asking ill people to voluntarily remain at home and not go to work or out into the community for about 7-10 days, or until they are well and can no longer spread the infection to others (voluntary isolation).

- Asking members of households where a person is ill to voluntarily remain at home for about seven days (voluntary quarantine).

- Treating ill individuals and members of their households with influenza antiviral medications, if available.

- Dismissing students from public and private schools, colleges and universities, school-based activities, and childcare programs for up to 12 weeks.

- Reducing out-of-school social contacts and community mixing such as closing malls and movie theaters.

- Reducing contact between adults in the community and workplace, including, for example, canceling large public gatherings, religious services, and social events. This could also include temporarily changing workplace environments and schedules to avoid the interaction of a large number of people.

\section{Faith-based and Community-based Organizations}

During a severe influenza pandemic, people from communities all around the United States and the world will be asked to voluntarily avoid gathering because this could spread the virus. People will be asked to stay at home if they are sick and to minimize contact with others. The federal government cannot prepare for or respond to a severe pandemic alone. During such a health crisis, there may not be a sufficient number of doctors, nurses, hospital beds, or other countermeasures to go around. Many-if not most-communities will be affected, and as many as $40 \%$ of workers may be unable to work because of illness or their need to care for ill family members. FBCOs will be essential partners in protecting the public's health and safety by helping to ensure that people in need are provided for and that care is pro- vided in a way that minimizes stigma and other negative social responses. The following are areas where partner organizations can make important contributions.

\section{Food and Water}

Infected individuals and their families-because they will be required to stay at home for an extended period-will need access to food and water. The federal government recommends that individuals and families consider stockpiling a two-week supply of nonperishable food and water now, if possible. Those with more resources can consider obtaining supplies to support themselves and one or two other families. FBCOs can also plan to help with food distribution through local food banks and programs such as Meals-on-Wheels, which will be adapted to distribute supplies in a way that will limit human-tohuman contact within 6 feet.

\section{Childcare}

During a severe influenza pandemic, school may be dismissed to help contain the spread of disease. For example, class studies could continue at home, with lessons being delivered via computer. If this happens, children and teenagers should also avoid gathering in the community at shopping malls and other places. Many places of worship operate childcare, mothers' morning out programs, and childcare drop-off facilities. It is important to determine how the parents of children and the staff of the centers will be informed if a facility is temporarily closing. Congregations, co-workers, friends, families and neighbors can work together to supervise and provide care for small groups of infants and young children. When possible, to minimize child-to-child contact, children should be cared for in multiple rooms, allowed to play in well-ventilated rooms, and encouraged to play outdoors with supervision. It is also useful to plan what equipment or books may be needed to teach and entertain children at home.

\section{Communication}

During a pandemic, FBCOs can play a vital role in maintaining community morale and cohesion, especially if mass gatherings and other community assemblies are cancelled. More than ever, people will need to be able to communicate with loved ones and receive timely information. We know from risk com- 
munication research that people are likely to turn to their religious and community leaders for reliable information during a health emergency. It will be useful for congregations and organizations to have internet, telephone and email access, and contact information. Realistically, not everyone will have access to internet-based communications, but lack of this technology should not stop organizations from planning how to communicate during an emergency. Mailed newsletters, prerecorded messages from trusted leaders on a designated call-in telephone number, and printed copies of daily teaching guides from trusted leaders may be options to reach those without internet access. Lay communication leaders can use telephone committees to provide information. FBCOs can work with state, local, tribal and territorial health departments to help ensure that timely and accurate information is available to community members in ways that are easy to understand, and in the context of shared values and honored traditions.

\section{Work}

Cross-training of staff and volunteers can help ensure that essential jobs will be covered if people must miss work during a severe pandemic. FBCOs should have up-to-date contact information for staff, volunteers, and members or clients. This information should include names of family members; addresses; home, work, and cell phone numbers; email addresses; and emergency contacts.

When planning budgets, FBCOs should consider an influenza pandemic among the host of unforeseen emergencies-such as fires and natural disasterswhich can potentially cause financial deficits.

Many congregations and organizations rely on community support of their activities. Such organizations will want to develop strategies in advance of a severe influenza pandemic that will allow and encourage people to make contributions through the mail, via the internet, or by some other alternate means if those people must stay at home for an extended period.

Some jobs can be performed at home. A system using emailed, mailed, or telephoned messages to homebound staff and volunteers can be used to relay communication or work assignments. For jobs that cannot be performed from home, flexible work hours and schedules (e.g., staggered shifts) can be set up to limit the number of people who must gather at the workplace at one time.

\section{Caring for the Sick}

Influenza is primarily treated by treating the symptoms, treating other infections that may afflict someone who is sick with influenza, and addressing any other medical conditions the person might have, such as heart disease or diabetes. FBCOs can help their neighbors, staff, volunteers, and members or clients to keep their own up-to-date list of medical conditions and medications. People should periodically check their supply of regular prescription and over-the-counter drugs to make sure they will have a sufficient supply during an emergency. It is important for people to seek healthcare if they become ill after traveling and to inform their healthcare provider of the places they have visited.

When started with 48 hours after the onset of influenza symptoms, antiviral medications may reduce influenza symptoms and shorten the time of illness. During the course of an influenza pandemic, the CDC and other laboratories will test pandemic strains to determine whether antiviral medications are useful against these strains. Once medications are available, FBCOs can work with state, local, tribal and territorial health departments to help ensure that medical treatments are provided and distributed equitably.

\section{Facilities}

Some religious schools are already working with county health departments so that during a severe pandemic their buildings can be used as vaccination clinics, antiviral distribution centers, triage centers, and for hospitals and morgues. FBCOs should work with state and local health departments to determine other ways their facilities might be used during a severe pandemic, such as temporary care facilities or central distribution sites for food, water, supplies, or medicine.

\section{Spiritual and Emotional Care}

Providing counseling and other ways to reduce stress will be a vital role for FBCOs during a pandemic event. Staff and volunteers of faith-based organizations may be asked to provide support to ill persons, their family members, and congregational leaders who will be under increased stress. 
Philosophical and theological questions may arise about why innocent people suffer. Those who have lost loved ones may need support working through the grieving process. FBCOs can develop or identify an existing mental health or counseling hotline that people in the community can call during a pandemic or other emergency. FBOCs can also work with community leaders to assure that materials developed related to resilience, disasters, and coping are culturally and ethnically sensitive, and are available in a variety of languages. Trusted community leaders can work to decrease the stigma associated with using mental health resources. FBOCs may also be called upon to provide support to emergency responders. While the work of emergency responders is personally rewarding, it also has the potential to affect responders in harmful ways. The long hours, stressful needs and demands, ambiguous roles, and the extensive exposure to human suffering can adversely affect even the most seasoned professionals.

\section{Vulnerable Populations}

Groups already vulnerable to ill health ${ }^{2}$ may be even more at risk during a severe influenza pandemic because of both the illness itself and the burdens associated with containment efforts. CDC's Pandemic Influenza Working Group on Vulnerable Populations describes these groups as those who are at high risk for exposure, complications, and death and may need assistance to prepare and respond because of social or medical disadvantages. Specific vulnerable populations will vary in each community and could include people with disabilities; chronic diseases or infections such as human immuniodeficiency virus/aquired immune deficiency syndrome (HIV/AIDS), tuberculosis, or hepatitis; pregnant women; inmates of prisons and jails; homeless persons; immigrants; refugees and those with limited English proficiency; single-parent families; public housing residents; migrant- farm-, and other lowwage workers; and racial and ethnic minority populations and tribes of Indian Country. The following are a few examples of groups likely to incur special need:

\section{People who Rely on Public or Congregational Assistance}

Individuals associated with FBCO should get to know which of their neighbors, co-workers, employ- ees, volunteers, and members or clients might need extra assistance due to economic hardships while sheltering at home during a severe influenza pandemic. Some congregations and organizations have a great deal of experience working with underserved communities. For example, various organizations that oversee homeless shelters and apartment complexes for low-income senior citizens are already planning to provide housing for the poor and developing sanitary practices to reduce the spread of infection within these facilities. Plans are also being made on how to assist those who live alone, single parents, and children who might become orphaned during a pandemic. If this is not a specific FBCO's main area of expertise, it may still be able to contribute by learning about and meeting with these groups to develop collaborative efforts.

\section{People Who are Vulnerable Due to Disabilities}

Individuals associated with a FBCO should get to know their neighbors, co-workers, employees, volunteers, and members or clients who have disabilities, especially those who live alone or those having health problems. When planning, FBCOs should remember to account for its own employees and volunteer staff members who may be unavailable because they need to stay home to care for disabled family members.

\section{Partnerships}

It is important to realize that government, communities, and individuals must work together to prepare for and respond to an influenza pandemic. A FBCO does not need to do everything by itself. Rather, it should be one part of a community, local, regional, and national collaborative effort. One of the most important things that a FBCO can do is to get to know and work with its state, local, tribal, or territorial health department. It can also work with elected officials, emergency responders, law enforcement organizations, healthcare systems, schools, businesses, and other FBCOs.

State, local, tribal, and territorial officials are developing, improving, and testing plans for pandemic influenza and will lead the response in their areas. The U.S. Department of Health and Human Services and other federal agencies are supporting state and local pandemic preparedness and response planning and are providing funding, advice, and 
other support to state, local, tribal, and territorial governments. 3,4

Many hospital and healthcare systems, law enforcement and emergency responder organizations, schools, and businesses are also actively preparing for an influenza pandemic. For example, hospitals are planning how to deal with large numbers of people who become ill simultaneously. Businesses are planning how to continue operating during an emergency. However, many of these groups may be unaware that a FBCO could offer valuable resources to its communities during a pandemic. These potential partners should be identified and met with to learn about their planning and to educate them about the FBCO's plans and capabilities. FBCOs should tell these organizations about practices that may be important to their constituency during a pandemic, such as rituals related to the death of a loved one. FBCOs can partner with congregations or organizations within their existing associations, networks or denominations, and within their neighborhoods. Methods to disseminate collaborative efforts-such as large organizations supporting smaller ones or several smaller organizations working together-need to be developed to keep organizations running during an emergency. State, local, tribal, or territorial government will be able to help FBCOs coordinate with other national and local pandemic preparedness efforts in their community.

\section{Conclusion}

The CDC and other leading public health organizations say the threat of a pandemic is real and warrants prudent preparedness planning. FBCOs will be key partners in protecting the public's health and safety if an influenza pandemic occurs. Individual and collective leadership are essential in encouraging people to prepare now for an influenza pandemic.

\section{Disclaimer}

The findings and conclusions in this report are those of the author and do not necessarily represent the views of the funding agency.

\section{Acknowledgements}

The author would like to thank the following individuals for helpful reviews, comments and information:

Richard Dixon, MD, associate director for science, Division of Partnerships and Strategic Alliances, $\mathrm{CDC} / \mathrm{CCHIS} / \mathrm{NCHM}$,

Lisa Koonin, MN, MPH, chief, Private Partnerships Branch, Division of Partnerships and Strategic Alliances, CDC/CCHIS/NCHM,

Stephanie Marshall, MSW, director of pandemic communications, Office of the Assistant Secretary for Public Affairs, U.S. Department of Health and Human Services, and

Dan Rutz, MPH, acting director, Division of Partnerships and Strategic Alliances, CDC/CCHIS/NCHM.

\section{References}

1. Centers for Disease Control and Prevention. Interim Pre-pandemic Planning Guidance: Community Strategy for Pandemic Influenza Mitigation in the United States-Early, Targeted, Layered Use of Nonpharmaceutical Interventions. [cited 2007 July 2]; Available from: www.pandemicflu.gov/plan/community/community_mitigation.pdf.

2. Cutter SL, Boruff BJ, Shirley WL. Social vulnerability to environmental hazards. Social Science Quarterly. 2003 June; 84(2):242-61.

3. U.S. Homeland Security Council. National Strategy for Pandemic Influenza Implementation Plan. 2006 [cited 2007 July 2]; Available from: www.whitehouse.gov/homeland/nspi_implementation.pdf.

4. U.S. Department of Health and Human Services. HHS Pandemic Influenza Plan. 2005 [cited 2007 July 2]; Available from: www.hhs.gov/pandemicflu/plan/. 
Table. Sources of Additional Information.

1. The Faith-Based and Community Organizations Pandemic Influenza Preparedness Checklist (available at http://www.pandemicflu.gov/plan/community/faithcomchecklist.html) provides an approach to pandemic planning by FBCOs. If a pandemic influenza event occurs, reliable, accurate, and timely information on the status and severity of the pandemic also will be posted on www.pandemicflu.gov.

2. Additional information is available from the Centers for Disease Control and Prevention (CDC) Hotline: 1800-CDC-INFO (1-800-232-4636). This line is available in English and Spanish, 24 hours a day, 7 days a week. TTY: 1-888-232-6348. Or, questions may be emailed to cdcinfo@cdc.gov.

3. Information about:

- Seasonal influenza. Centers for Disease Control and Prevention. http://www.cdc.gov/flu/keyfacts.htm and http://www.pandemicflu.gov/season.

- Avian influenza. Centers for Disease Control and Prevention. http://www.cdc.gov/flu/avian/.

- Antiviral medications. U.S. Department of Health and Human Services. Medications/Antivirals. http://www.pandemicflu.gov/vaccine/medantivirals.html.

- Vaccines. U.S. Department of Health and Human Services. Vaccines and Vaccine Research. http://www.pandemicflu.gov/vaccine/vacresearch.html.

- Washing hands. Centers for Disease Control and Prevention. Clean Hands Save Lives! http://www.cdc.gov/cleanhands/.

- Cough and sneeze etiquette: Centers for Disease Control and Prevention. Cover Your Cough. http://www.cdc.gov/flu/protect/covercough.htm.

- Guidance on Preparing Workplaces for an Influenza Pandemic. OSHA 3327-02N 2007. U.S. Department of Labor Occupational Safety and Health Administration. Provides guidance and recommendations on infection control in the workplace, including information on proper mask and respirator use. http://www.osha.gov/Publications/OSHA3327pandemic.pdf.

- Health Recommendations for International Travel. Centers for Disease Control and Prevention. Visit CDC's Travelers' Health Website www.cdc.gov/travel/ for education regarding traveling and disease risks.

4. Centers for Disease Control and Prevention. Interim Prepandemic Planning Guidance: Community Strategy for Pandemic Influenza Mitigation in the United States - Early, Targeted, Layered Use of Nonpharmaceutical Interventions http://www.pandemicflu.gov/plan/community/community_mitigation.pdf.

5. Creating a Pandemic Preparedness Movement. The U.S. Department of Health and Human Services is engaging influential leaders from the business, faith-based, civic, and health-care sectors to help them confidently spread the word about the critical need for individual preparedness. For more information on the campaign and how to get involved, visit http://www.pandemicflu.gov/plan/federal/forum.html.

6. Spiritual and Emotional Care

- A Guide for Spiritual Care in Times of Disaster for Disaster Response Volunteers, First Responders and Disaster Planners. The National Voluntary Organizations Active in Disaster (National VOAD) has developed this useful guide. http://www.nvoad.org/articles/Light_Our_Way_LINKS.pdf

- Gurwitch, R. H., Pfefferbaum, B., Montgomery, et al. Building Community Resilience for Children and Families. Oklahoma City: Terrorism and Disaster Center at the University of Oklahoma Health Sciences Center. 2007.http://www.nctsn.org/nctsn_assets/pdfs/edu_materials/BuildingCommunity_FINAL_02-12-07.pdf.

7. The disability preparedness Web site provides information on how people with disabilities, their family members and service providers can prepare for emergencies. The site also includes information for emergency planners and first responders to help them to better prepare for serving persons with disabilities. Interagency Coordinating Council on Emergency Preparedness and Individuals with Disabilities. http://www.disabilitypreparedness.gov/. 
Table. Continued.

8. Ethical considerations relevant to public health decision-making during planning for and responding to pandemic influenza. http://www.cdc.gov/od/science/phec/guidelinesPanFlu.htm.

9. Information on how to contact important agencies in your state: U.S. Department of Health and Human Services. Contact Information for State Departments of Agriculture, Wildlife, and Public Health. http://www.pandemicflu.gov/plan/states/statecontacts.html.

10. U.S. Department of Health and Human Services. Pandemic Influenza Planning Checklists for Home Health Care Services, Medical Offices and Clinics Checklist, Emergency Medical Services and Non-emergent (Medical) Transport Organizations, Hospitals, Long-Term Care and Other Residential Facilities, and Health Insurers. http://www.pandemicflu.gov/plan/healthcare/index.html.

\section{IMANA Pledges Support of FBCO Plan to Manage Pandemic}

Editorial Comment: Pandemics of influenza have occurred for many centuries. The 1918 pandemic was devasting, and experts have concluded that we are due for another outbreak. This article by Dr. Scott Santibañez from the Centers for Disease Control and Prevention presents an overview of the problem along with the measures that faithbased organizations can take to limit the devastation. These measures are simple and practical and involve locallevel leadership.

The article is well written, and I recommend that we take this information to our local communities and begin the process of education and planning. There will be some challenges in implementing some of the plans, but these can be solved with the right approach. The leadership at IMANA pledges to fully cooperate with the CDC in the plan to limit the effect of a pandemic.

\section{Sheik N. Hassan, MD, FCCP}

Associate Dean for Academic Affairs

Immediate Past President, IMANA 